\title{
Histologia do rim, fígado e intestino de girinos de rã-touro (Rana catesbeiana) alimentados com dietas contendo própolis
}

\author{
Histology of kidney, liver and intestine of bullfrog tadpoles (Rana catesbeiana) fed with diets \\ containing propolis \\ Luis Ricardo Romero Arauco ${ }^{\mathrm{I}}$ Marta Verardino De Stéfani ${ }^{\mathrm{II}}$ Laura Satiko Okada Nakaghi ${ }^{\mathrm{II}}$ \\ Verônica Regina Lobato de Oliveira-Bahia ${ }^{\mathrm{I}}$
}

\section{RESUMO}

Este trabalho teve como objetivo verificar a ocorrência de possíveis alterações no fígado, rim e intestino de girinos de rã-touro no estágio 42, alimentados com dietas contendo diferentes concentrações $(0,0 ; 0,2 ; 0,5 ; 1,0 ;$ e 1,5\%) de extrato hidroalcoólico de própolis. $O$ experimento foi conduzido no laboratório de Nutrição de Organismos Aquáticos do Centro de Aqüicultura da UNESP, onde foram utilizados 1.400 girinos no estágio 26, distribuídos em vinte tanques experimentais. No final do experimento (60 dias), foram sacrificados três girinos de cada repetição e retiradas amostras de rim, fígado e intestino para processamento de lâminas histológicas no Laboratório de Histologia do Departamento de Morfologia e Fisiologia Animal da FCAV - UNESP. As amostras foram fixadas, desidratadas, coradas com HE, analisadas, fotomicrografadas e medida a espessura do epitélio intestinal. Não foram observadas alterações histológicas no intestino, rins e fígado dos girinos. A espessura do epitélio do intestino dos mesmos não foi influenciada $(P>0,05)$ pelas concentrações de própolis.

Palavras-chaves: ranicultura, histologia, própolis, órgãos.

\section{ABSTRACT}

This research was aimed at verifying the occurrence of possible alterations in liver, kidney and intestine of bullfrog tadpoles in stage 42 fed with diets containing different concentrations $(0.0 ; 0.2 ; 0.5 ; 1.0$ and $1.5 \%)$ of propolis hydroalcoholic extract. The experiment was carried out in laboratory of Aquatic Organisms Nutrition from Aquaculture Center of UNESP, where 1,400 tadpoles in stage 26 were used and distributed in twenty experimental aquariums. In the end of experiment (60 days) three tadpoles from each repetition were sacrificed and kidney, liver and intestine samples were collected to processing of histological slices in Histology's Laboratory pertaining to Department of Morphology and Physiology from FCAV - UNESP. Samples were fixed, dehydrated, stained in HE, analysed, photomicrographed and thickness of intestinal epithelium was measured. Histological disturbances in tadpoles's intestine, kidneys and liver were not observed. Thickness of intestinal epithelium from the same ones was not influenced $(P>0.05)$ by propolis concentrations.

Key words: frogculture, histology, propolis, organs.

\section{INTRODUÇÃO}

A própolis de Apis melífera contém vários componentes ativos naturais que apresentam uma variedade de efeitos como: o antimicrobiano (KOO et al., 2000), o efeito protetor contra danos induzidos por radiação (EL-GHAZALY \& KHAYYAL, 1995), o antimutagênico (VARANDA et al., 1999), O antiinflamatório (OZTURK et al., 2000), o hepatoprotetor (EL-KHATIB, et al., 2002), antitumoral (ORSOLIC \& BASIC, 2003) o imunoestimulante e o antiviral (ORSI et al., 2005). A maioria desses efeitos estão relacionados com as propriedades antioxidantes presente na própolis (BASNET et al., 1997).

'Programa de Pós-graduação em Aqüicultura, Centro de Aqüicultura, Universidade de São Paulo (UNESP), CAUNESP, Jaboticabal, São Paulo, Brasil.

"Departamento de Zootecnia, CAUNESP, Faculdade de Ciências Agrárias e Veterinárias (FCAV), UNESP, Jaboticabal, São Paulo, Brasil

IIIDepartamento de Morfologia e Fisiologia Animal, CAUNESP, FCAV, UNESP, Via de acesso Prof. Paulo Donato Castellane, s/n, 14884-900, Jaboticabal, SP, Brasil. E-mail:laurankg@fcav.unesp.br. Autor para correspondência. 
O tipo de rim desenvolvido pelos girinos corresponde ao pronefro e está composto de nefrons, constituindo a unidade funcional do rim. Possui cápsula, túbulo renal e tecido hematopoiético (GEORGE et al., 1998).

A organização histológica básica do fígado do girino e do adulto consiste em arranjo dos hepatócitos em cordões contendo sinusóides e células de Kupffer. O espaço perisinusoidal é delimitado por células endoteliais e hepatócitos. O tecido hepático não sofre mudança durante e depois da metamorfose (VIERTEL \& RICHTER, 1999).

O intestino dos girinos de rã-touro é composto pela camada mucosa, formada por epitélio simples com células cilíndricas com borda em escova, células caliciformes e linfócitos intraepiteliais; pela submucosa, constituida por células, fibras colágenas e diversos vasos sangüíneos; pela muscular, formada por músculo liso em disposição circular, e pela camada serosa, constituída por tecido conjuntivo e células pavimentosas (OLIVEIRA-BAHIA et al., 2005).

Alterações morfológicas celulares no fígado, rim e intestino podem ser provocadas por substâncias químicas e drogas, as quais são importantes causas de adaptações, lesão e morte celular. Existem três tipos de adaptação celular que são: atrofia, hipertrofia e hiperplasia. Os tipos de lesões celulares são: tumefação celular, esteatose, necrose (coagulativa, de liquefação e caseosa) e apoptose (KUMAR et al., 1994).

A alimentação de camundongos com ração contendo álcool e extrato alcoólico de própolis não alterou o ganho de peso, e não foram observados sintomas clínicos de intoxicação nem anormalidades histológicas no fígado (HOLLANDS et al., 1991).

Como não foi encontrada até o momento nenhuma citação sobre a ação da própolis em girinos, o presente trabalho teve como objetivo verificar a ocorrência de possíveis alterações histológicas no rim, fígado e intestino, bem como na espessura do epitélio intestinal de girinos de rã-touro submetidos a dietas com diferentes concentrações de extrato hidroalcólico de própolis.

\section{MATERIAL E MÉTODOS}

O experimento foi conduzido no Laboratório de Nutrição de Organismos Aquáticos do Centro de Aqüicultura da UNESP e as análises histológicas no laboratório de histologia do Departamento de Morfologia e Fisiologia Animal da FCAV/UNESP, Campus de Jaboticabal.
Foram utilizados 1.400 girinos de rã-touro, Rana catesbeiana, com peso médio de $0,08 \mathrm{~g}$ no estágio 26 de GOSNER (1960), procedentes de uma mesma desova. Os animais foram distribuídos em 20 tanques experimentais com 70 litros de água, na densidade de um girino por litro de água.

Os girinos foram alimentados durante 60 dias com ração comercial contendo $45 \%$ de proteína bruta (Poli peixe $450 \mathrm{~F}$ ), em pó e peneirada em malha de $2 \mathrm{~mm}$, na qual foram adicionadas e misturadas manualmente diferentes concentrações do extrato hidroalcoólico de própolis $(0,0 ; 0,2 ; 0,5 ; 1,0 ; 1,5 \%)$ adquirido na empresa Apis Flora Industrial e Comercial LTDA, localizada em Ribeirão Preto-SP, apresentando as seguintes características: aspecto = líquido límpido, sem partículas em suspensão; cor = âmbar; $\mathrm{pH}=5,35$; teor alcoólico $=56 \%$; propriedade antioxidante $=8$ segundos; sólidos solúveis $=11 \mathrm{P} / \mathrm{V} \%$; flavonóides totais $=5,45 \mathrm{mg} \mathrm{L}^{-1}$. Após esse procedimento, as rações foram secadas em estufa com circulação de ar a $40^{\circ} \mathrm{C}$ por 24 horas e, logo após, trituradas em liquidificador por dois minutos e estocadas em freezer.

O arraçoamento foi a lanço, de modo uniforme, quatro vezes ao dia. Antes da alimentação diária, os tanques foram limpos para a retirada dos dejetos e restos da alimentação anterior. No decorrer do experimento, a temperatura da água dos tanques foi aferida diariamente com termômetro digital e, semanalmente, realizou-se análise de água medindo-se o pH, a condutividade elétrica (mediante Horiba) e o oxigênio dissolvido (oxímetro Hach DO meter 16046).

No final do período experimental (60 dias), foram sacrificados nove girinos de cada tratamento no estágio 42 (GOSNER, 1960), e retiradas amostras do rim, fígado e intestino. O exame foi realizado primeiramente por inspeção visual, procurando-se alterações macroscópicas tais como: coloração e consistência dos órgãos.

Posteriormente, as amostras desses órgãos foram fixadas em solução de formol tamponado a $10 \%$. Após fixação, procedeu-se à lavagem em álcool $70^{\circ} \mathrm{GL}$ para desidratação em série alcoólica crescente, diafanização em série de xilóis, inclusão em parafina, microtomia de $5 \mu \mathrm{m}$ e coloração pela técnica da Hematoxilina-eosina (HE).

Os cortes histológicos foram analisados e fotomicrografados com fotomicroscópio AxioskopZeiss. Ao microscópio de luz foram observadas suas estruturas e alterações microscópicas, baseadas em KUMAR et al. (1994) e VIERTEL \& RICHTER (1999). Foram realizadas quatro medidas por lâmina da espessura do epitélio intestinal dos girinos em microscópio de luz acoplado a uma ocular micrométrica e objetiva de $40 \mathrm{x}$. 
Para análise dos dados da espessura do epitélio do intestino dos girinos de rã-touro, foi utilizado o delineamento inteiramente ao acaso, com cinco tratamentos (dietas com concentrações de 0,$0 ; 0,2 ; 0,5$; 1,0 e $1,5 \%$ de própolis) e três repetições. A análise estatística dos dados foi realizada por meio da análise de variância e as médias comparadas pelo Teste de Tukey.

\section{RESULTADOS E DISCUSSÃO}

\section{Características hidrológicas}

A temperatura média da água dos tanques durante o período experimental variou de $28,27 \pm 0,45$ a $28,77 \pm 0,34^{\circ} \mathrm{C}$. Esses valores estão próximos daqueles observados por CASTRO \& PINTO (2000), podendo ser considerados satisfatórios ao desenvolvimento dos girinos.

De maneira geral, os parâmetros físicoquímicos da água apresentaram-se relativamente constantes nos diferentes tratamentos. Os teores médios de oxigênio dissolvido variaram de $5,75 \pm 0,33$ a $6,06, \pm 0,67 \mathrm{mg} \mathrm{L}^{-1}$, estando dentro do limite aceitável para o cultivo de organismos aquáticos $(6,5$ a 6,9$)$, segundo CULLEY Jr. (1981). Os valores médios de $\mathrm{pH}$ variando de 7,3 $\pm 0,17$ a 7,6 $\pm 0,06$ também estão próximos ao valor recomendado para o cultivo de girinos de 7,4, segundo HAYASHI et al. (2004). A condutividade elétrica da água dos tanques experimentais variou de $190,2 \pm 5,52$ a $195,1 \pm 4,94 \mu \mathrm{S} \mathrm{cm}^{-1}$.

\section{Características morfológicas}

O exame macroscópico do rim de todos os girinos deste experimento apresentou aparência normal, com coloração rosa-vermelha e consistência firme.

Nas figuras 1A e 1B, observa-se que o rim de girinos no estágio 42 de GOSNER (1960) é formado por diferentes estruturas: cápsula de Bowman, constituída por espaço capsular, folhetos parietal e visceral, podócitos, glomérulo, vasos sanguíneos e células sanguíneas. Além dessas estruturas há tecido hematopoético, túbulos e néfron.

No grupo de girinos controle (Figura 1A) e no grupo tratado com $1,5 \%$ de extrato hidroalcoólico de própolis (Figura 1B) sob microscopia de luz, não foram observadas alterações histológicas nas diferentes estruturas do rim.

A aplicação clínica de própolis em coelhos, chinchila e camundongos foi estudada por SCHELLER et al. (1977) e HOLLANDS et al. (1991), os quais não observaram anormalidades histológicas nos diversos órgãos analisados nem sintomas clínicos de intoxicação ou alterações no ganho de peso.
Os girinos deste experimento apresentavam macroscopicamente figado aparentemente normal, com coloração marrom avermelhada e consistência firme.

$\mathrm{Na}$ análise histológica do fígado dos girinos do grupo controle (Figura 1C) e tratados com extrato hidroalcoólico de própolis (Figura 1D), observou-se todos os componentes estruturais como: hepatócitos. e seus núcleos, citoplasma contendo grânulos de glicogênio, pequenos vacúolos; veia, células sangüíneas e ductos. Não se verificou lesão celular nos hepatócitos dos girinos causada pelo consumo de extrato hidroalcoólico de própolis na ração (Figura 1D).

Devido à ausência de informações sobre o efeito da própolis no fígado e demais órgãos de girinos, utilizou-se, para a discussão dos dados, trabalhos em outras espécies. O efeitohepato protetor do extrato aquoso de própolis foi demonstrado em ratos por ELGHAZALY \& KHAYYAL (1995), afirmando a importância deste para a conservação da biomembrana dos hepatócitos.

Foram observados por CAPUCHO et al. (2005) tumefação celular, pequenos vacúolos e necrose do parênquima hepático em ratos tratados com $10 \mathrm{mg}$ $\mathrm{kg}^{-1} \mathrm{dia}^{-1}$ de extrato de própolis.

Os hepatócitos apresentaram vacúolos e grânulos de glicogênio no grupo controle e nos tratados com própolis (Figura 1C e 1D). VIERTEL \& RICHTER (1999) indicaram que os hepatócitos apresentam alto conteúdo de substância nutritiva e gotas de lipídio em girinos no estágio 24 de GOSNER (1960).

Nas figuras 1E e 1F observa-se que a histologia do intestino dos girinos no estágio 42 (GOSNER, 1960) está composta pela camada mucosa, constituída por epitélio cilíndrico simples com borda em escova e células caliciformes, com lâmina própria contendo linfócitos intraepiteliais; pela submucosa formada por células, fibras colágenas e vasos sanguíneos; pela camada muscular de músculo liso em disposição circular e externamente à camada serosa, caracterizada por tecido conjuntivo e células pavimentosas.

$\mathrm{Na}$ figura $1 \mathrm{~F}$ dos girinos tratados com $1,5 \%$ de própolis, não se observou adaptação, alteração ou lesão celular no intestino dos mesmos.

A espessura do epitélio intestinal dos girinos nos diferentes tratamentos encontra-se na tabela 1. A análise mostrou que a espessura do epitélio intestinal não foi influenciada $(\mathrm{P}>0,05)$ pelas diferentes concentrações de própolis testadas neste experimento.

$\mathrm{Na}$ literatura consultada, não foram encontrados dados referentes à espessura do epitélio intestinal em anfíbios para a comparação com os resultados obtidos. 


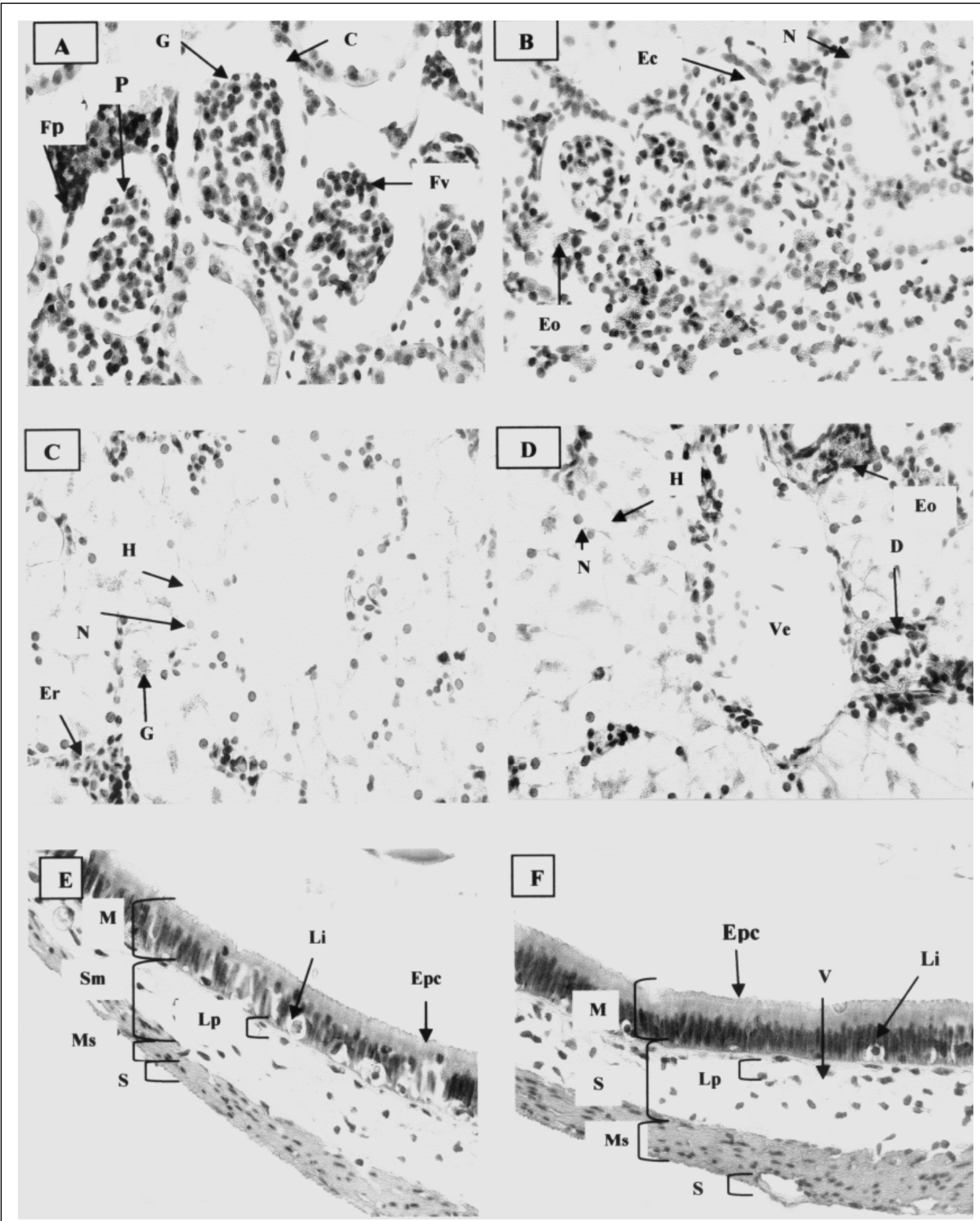

Figura 1 - A e B: Rim (pronefro) de girino de Rana catesbeina no estágio 42 de Gosner (A=animais-controle; B=animais tratados com $1,5 \%$ de própolis); $\mathrm{C}$ e $\mathrm{D}$ : Fígado ( $\mathrm{C}=$ animais-controle; $\mathrm{D}=$ animais tratados com $1,5 \%$ de própolis); $\mathrm{E}$ e $\mathrm{F}$ : Intestino ( $\mathrm{E}=$ animais-controle; $\mathrm{F}=$ animais tratados com $1,5 \%$ de própolis). H.E. $400 \mathrm{x}$.

$\mathrm{G}=$ Glomérulo, $\mathrm{C}=$ Cápsula de Bowman, $\mathrm{Ec}=$ Espaço capsular, $\mathrm{P}=$ Podócito, $\mathrm{Fp}=$ Folheto parietal, $\mathrm{Fv}=$ Folheto visceral, $\mathrm{N}=$ Nefron; $\mathrm{H}=$ Hepatócito, $\mathrm{N}=$ Núcleo do hepatócito, $\mathrm{Ve}=$ Veia, Eo=Eosinófilo, $\mathrm{Er}=$ Eritrócito, $\mathrm{D}=\mathrm{Ducto}, \mathrm{Epc}=$ Epitélio colunar simples, $\mathrm{Li}=$ Linfócito intraepitelial, $\mathrm{Lp}=$ Lâmina própria, $\mathrm{M}=$ Mucosa, $\mathrm{Sm}=$ Submucosa, $\mathrm{Ms}=$ Muscular, $\mathrm{S}=$ Serosa, $\mathrm{V}=$ Vaso. 
Tabela 1 - Valores de (F), coeficiente de variação (CV) e médias da espessura do epitélio intestinal $(\mu \mathrm{m})$ dos girinos de rã-touro nos diferentes tratamentos.

\begin{tabular}{lcc}
\hline & & $\begin{array}{c}\text { Espessura do epitélio intestinal } \\
(\mu \mathrm{m})\end{array}$ \\
\cline { 3 - 3 } \multicolumn{2}{l}{ F para Tratamentos } & $2,29 \mathrm{Ns}$ \\
\multicolumn{2}{l}{ CV $(\%)$} & 4,33 \\
\hline Médias & T1 $(0,0)$ & 40,66 \\
& T2 $(0,2)$ & 43,33 \\
& T3 $(0,5)$ & 42,66 \\
& T4 $(1,0)$ & 40,00 \\
& T5 $(1,5)$ & 40,00 \\
\hline
\end{tabular}

NS - não-significativo.

$\mathrm{T} 1=0,0 \%$ de própolis; $\mathrm{T} 2=0,2 \%$ de própolis; $\mathrm{T} 3=0,5 \% \mathrm{de}$ própolis ; $\mathrm{T} 4=1,0 \%$ de própolis; $\mathrm{T} 5=1,5 \%$ de própolis.

Em rã-touro adulta, HIPOLITO (2004) observou alterações histológicas do intestino por intoxicação nutricional com deficiência protéica, tais como descamações e atrofia das vilosidades do epitélio intestinal, o que não se observou no presente experimento em girinos alimentados com própolis.

Não foram observadas alterações macroscópicas e histológicas nos diferentes órgãos estudados de girinos de rã-touro, provavelmente devido às baixas concentrações de própolis utilizadas no presente estudo.

\section{CONCLUSÃO}

Mediante microscopia de luz não se observaram alterações celulares do epitélio dos rins, fígado e intestino, nem mudanças na espessura do epitélio do intestino de girinos de rã-touro submetidos a diferentes concentraçãoes de extrato hidroalcoólico de própolis.

\section{AGRADECIMENTOS}

À empresa Apis Flora Industrial e Comercial LTDA, pela doação do extrato hidroalcoólico de própolis.

\section{REFERÊNCIAS}

BASNET, P. et al. Potent free radical scavenging activity of propol isolated from Brazilian propolis. Z Naturforsch, Juebingen, v.52, n.1, p.828-855, 1997.

CAPUCHO, C. et al. Efect of the própolis in wistar rats liver. Braz J Morphol Sci, São Paulo, Supl. p.100, 2005.
CASTRO, J.C.; PINTO, A.T. Qualidade da água em tanques de girinos de rã-touro, Rana catebeiana Shaw, 1802, cultivados em diferentes densisdades de estocagem. Rev Bras Zootec, v.29, n.6, p.1903-1911, 2000 .

CULLEY Jr, D.D. Have we turned the corner on bullfrog culture? Aquacult Magaz, v.7, n.3, p.20-24, 1981.

EL-GHAZALY, M.A.; KHAYYAL M.T. The use of aqueous propolis extract against radiation-induced damage. Drugs Exp Clin Res, v.21, p.229-236, 1995.

EL-KHATIB, A.S. et al. Prophylactic effect of aqueous propolis extrat against acute experimental hepatotoxicity in vivo. $\mathbf{Z}$ Naturforsch, v.57, n.1, p.379-385, 2002.

GEORGE, L.L. et al. Histologia comparada. 2.ed. São Paulo: Roca, 1998. 286p.

GOSNER, K.L. A simplified table, for staging anura embryos and larvae with notes on identification. Herpetologica, Austin, v.16, n.2, p.183-190, 1960.

HAYASHI, C. et al. Desenvolvimento de girinos de rã-touro (Rana catesbeiana Shaw, 1802) cultivados em diferentes densidades de estocagem em tanque-rede. Rev Bras Zootec, v.33, n.1, p.14-20, 2004.

HIPOLITO, M. Avaliação bioquímica no desenvolvimento da rã-touro Rana catesbeiana (Shaw, 1802) tratada com dieta comercial e experimental. 2004. 84f. Tese (Doutorado em Biotecnologia)-Curso de Pós-graduação em Biotecnologia, Instituto de Química de Araraquara, Universidade Estadual Paulista.

HOLLANDS, I. et al. Demostración ultraestructural del efecto citohepatoprotector del propoleo. Rev Cubana Ciênc Vet, v.22, p.85-90, 1991.

$\mathrm{KOO}, \mathrm{H}$. et al. In vítro antimicrobial activity of propolis and Amrnica Montana against oral pathogens. Arch Oral Biol, v. 45, n.2, p.141-148, 2000 .

KUMAR, V. et al. Patologia básica. Rio de Janeiro: Guanabara Koogan, 1994. 608p.

OLIVEIRA-BAHIA, V.R.L. et al. Development of the gastroenteric region in Rana catesbeiana tadpoles during the metamorphosis process. Braz J Morphol Sci, v.22, Suppl, p.158-159, 2005.

ORSI, O.R. et al. Effect of brazilian and bulgarian própolis on bactecidal activity of macrophages against Salmonella typhimurium. Int Immunopharmacol, v.5, n,2, p.359-368, 2005.

ORSOLIC, N.; BASIC, I. Immunomodulation by water-soluble derivative of propolis: a factor of antitumor reactivity. J Ethnopharmacology, v.84, n.2, p.265-273, 2003. 
OZTURK, F. et al. The effect of propolis extract in experimental chemical corneal injury. Ophthalmic Res, v.32, p.13-18, 2000 .

SCHELLER, S. et al. Biological properties and clinical application of propolis. VII. Investigation of immunogenic properties of ethanol extrat of propolis. Arzneim-Forsch, v.27, p.12, 1977.
VARANDA, E.A. et al. Inhivitory effect of propolis and bee venom on the mutegenicity of some direct and indirect-acting mutagens. Teratog Carcinog Mutagen, v.19, n.6, p.403413, 1999

VIERTEL, B.; RICHTER, S. Anatomy viscera and endocrines. In: McDIARMID, R.W.; ALTING, R. Tadpoles the biology of anuran larvae. Chicago: University of Chicago, 1999. Cap.5, p.92-98. 